\title{
ESTIMATIVA DA ACIDEZ POTENCIAL PELO MÉTODO DO PH SMP EM SOLOS DA FORMAÇÃO CAIUÁ - NOROESTE DO ESTADO DO PARANÁ(1)
}

\author{
J . A. SAMBATTI (2), I. G. SOUZA J UNIOR ${ }^{(2)}$, \\ A. C. S. $\operatorname{COSTA}^{(3)} \&$ C. A. TORMENA(3)
}

\begin{abstract}
RESUMO
A utilização do pH SMP na estimativa da acidez potencial tem vantagens em relação ao método do acetato de cálcio $0,5 \mathrm{~mol} \mathrm{~L}^{-1}, \mathrm{pH} 7$, mas requer regionalização edafológica prévia para estimar, com segurança, os valores de H + Al. Na região noroeste do Paraná, encontram-se solos originários de uma rocha sedimentar arenosa da Formação Caiuá, denominada Arenito Caiuá, do período Cretáceo. E sses solos são caracterizados pelos baixos teores de argila, matéria orgânica e baixo tamponamento, diferindo da maioria dos solos existentes no estado. Este estudo teve por objetivo comparar os métodos do pH SMP e o do acetato de cálcio 0,5 mol L-1, pH 7, visando estabelecer uma equação que esti me a acidez potencial dos solos dessa área, por meio da obtenção do pH de equilíbrio da suspensão com a sol ução SMP. Cento e cinqüenta amostras de solos daquela área foram submetidas a análises de regressão, utilizando três modelos que foram avaliados, quanto à qualidade das estimativas, pelas estatísticas dos seus coeficientes e pelo comportamento dos seus resíduos (medido-estimado). A equação linear H $+\mathrm{Al}=20,1925-2,6484 \mathrm{pH}$ SMP $\left(\mathrm{R}^{2}=\right.$ 0,9051) foi a que melhor estimou a acidez potencial dos solos pertencentes à Formação Caiuá.
\end{abstract}

Termos de indexação: tamponamento, solos arenosos, química do solo, capacidade de troca catiônica, pH do solo.

\footnotetext{
(1) Recebido para publicação em abril de 2002 e aprovado em janeiro de 2003.

(2) Pós-Graduando em Agronomia, Universidade Estadual de Maringá - UEM. Av. Colombo 5790, CEP 87020-190 Maringá (PR). Bolsista do CNPq. E-mail: jasambatti @brturbo.com.br; igsjunior@uem.br

(3) Professor Adjunto do Departamento de Agronomia, UEM. Bolsista do CNPq. E-mail: acscosta@uem.br; catormena@uem.br
} 


\title{
SUMMARY: ESTIMATION OF POTENTIAL ACIDITY BY THE PH SMP METHOD IN SOILS OF THE CAIUÁ FORMATION - NORTHWEST OF THE STATE OF PARANÁ
}

\begin{abstract}
The use of the pH SMP to estimate the potential acidity has advantages in relation to the $0.5 \mathrm{~mol} \mathrm{~L}^{-1}, \mathrm{pH} 7$, cal cium acetatemethod, but it requires previous edaphic regionalization to estimatetheH +Al values with safety. In thenorthwestern region of theState of Paraná there are soils originally devel oped from sandy sedimentary rock of the Cai uá Formation, called Caiuá Sandstone, of the Cretaceous period. These soils are characterized by low contents of clay and organic matter, and a low buffer capacity, differing from most of the other soils in the state. The objective of this research was to compare the pH SMP and the $0.5 \mathrm{~mol} \mathrm{~L}^{-1}, \mathrm{pH} 7$ calcium acetatemethods, in order to establish an equation to estimatethe potential acidity of soils in this area, by determination of the equilibrium pH of the soil suspension with the SMP solution. One hundred and fifty soil samples of this area were submitted to regression analyses, evaluating threeregression models according to theestimate quality, by statistics of their coefficients and behavior of their resi dues (measured-esti mated). Thelinear equation $\mathrm{H}+\mathrm{Al}=20.1925-2.6484 \mathrm{pH}$ SMP $\left(\mathrm{R}^{2}=0.9051\right)$ esti mated thepotential acidity of Caiuá F ormation soils best.
\end{abstract}

Index terms: buffer capacity, sandy soils, soil chemi stry, cation exchange capacity, soil pH .

\section{INTRODUÇÃO}

Uma das propriedades mais importantes do solo é a de reter íons na interface sólido/sol ução do solo. Esta propriedade, quando se trata da troca de cátions, édenominada capacidade de troca catiônica (CTC). O conhecimento de sua magnitude é de grande relevância tanto do ponto de vista agrícola quanto ambiental. Vários métodos, diretos e indiretos, têm sido utilizados para a determinação da CTC; contudo, o procedimento freqüentemente utilizado nos laboratórios brasileiros de análises de solo para fins de fertilidade é o da soma de bases, $\mathrm{Ca}^{2+}, \mathrm{Mg}^{2+}, \mathrm{K}^{+}, \mathrm{Na}^{+}$, mais a acidez potencial $(\mathrm{H}+$ $\mathrm{Al})$, extraídos por diferentes métodos químicos.

Os componentes da acidez potencial dos solos, $\mathrm{H}$ e Al, são determinados, geralmente, mediante extração com soluções de sais tamponantes ou misturas de sais neutros com solução-tampão. Na maioria dos laboratórios brasileiros de análises de sol o, utiliza-se a solução de acetato de cálcio 0,5 mol L-1, $\mathrm{pH} 7$. No entanto, este método apresenta algumas limitações, tais como: a difícil visualização do ponto de viragem do indicador durantea titulação (Pereira et al., 1998), a elevada quantidade de acetato de cálcio consumida por amostra, o que resulta em aumento do custo da análise (Silva et al., 2000), a el evada demanda de tempo operacional, decorrente das etapas de extração e determinaçãotitulométrica, o que dificulta a automação do processo (Pavan et al., 1996; Escosteguy \& Bissani, 1999). Além disso, subestimativas dos valores de $\mathrm{H}+\mathrm{Al}$ em solos com $\mathrm{pH}$ acima de 6,0 podem ser devidas ao deficiente tamponamento da solução de acetato de cálcio em valores de pH próximos de 7,0 (Raij, 1991).
Em diversos países, a solução-tampão SMP (Shoemaker et al., 1961) é o método mais utilizado na avaliação da acidez potencial. Apesar deter sido inicialmente desenvolvida para determinar a necessidade de calagem e estar sendo amplamente difundida para este fim (Raij et al., 1979; Sousa et al., 1980; Ernani \& Almeida, 1986), o método SMP vem sendo cada vez mais empregado no B rasil para a avaliação da acidez potencial. I sso se deve, principal mente, à simplicidade, rapidez, baixo custo e eficiência desse método.

Com vistas em estimar a acidez potencial de solos de diferentes estados e regiões brasileiras, vários estudos têm sido desenvolvidos por meio do pH SMP. Quaggio et al. (1985) apresentaram o modelo de equação para o estado de São Paulo, Corrêa et al. (1985), para o estado de Minas Gerais; Sousa et al. (1989), para os cerrados; Pavan et al. (1996), para o estado do Paraná; Maeda et al. (1997), para o estado do Mato Grosso do Sul; Escosteguy \& Bissani (1999), para os estados do Rio Grande do Sul e Santa Catarina; Nascimento (2000), para o estado de Pernambuco; Silva et al. (2000), para sol os do semiárido do nordestebrasileiro, eSilva et al. (2002), para os sol os da região norte do estado de Minas Gerais.

Nestes trabalhos, observou-se, que dentre os model os matemáticos utilizados para relacionar os valores de $\mathrm{H}+\mathrm{Al}$ e o pH SMP, predominam os que usam regressão exponencial e polinomial de segunda ordem. Na maioria dos trabalhos publicados, os autores preocuparam-se muito mais em observar o ajuste dos model os utilizados em relação aos dados obtidos do que avaliar a sua qualidade para decidir sobre sua adoção ou modificação. Segundo Montgomery \& Peck (1992), a avaliação da 
qualidade de um modelo envolve não somente a observação do coeficiente de determinação $\left(R^{2}\right)$, mas tambéma significância estatística de seus coeficientes ea avaliação dos resíduos produzidos pel os modelos.

As diferentes equações de correlação obtidas nesses trabal hos evidenciam a influência de al gumas características dos solos na relação entre estas variáveis. Neste contexto, Escosteguy \& Bissani (1999) ressaltaram a necessi dade de regionalização dos estudos, em virtude da variação do poder-tampão entre sol os de diferentes composições, com destaque para o teor etipo de matéria orgânica, textura, tipo e quantidade de minerais da fração argila e pH. Ainda, de acordo com Pavan et al. (1996) e Quaggio \& Raij (2001), o uso deste método deve ser precedido de uma regi onal ização edafológica prévia, para obter curvas de cali ibração específicas.

A região noroeste do estado do Paraná ocupa $18 \%$ da área total do estado, abrange 100 municípios e totaliza 3.510.800 hectares (E mater-Paraná, 1998), dos quais, aproximadamente, 2.640 .000 hectares são formados a partir de rochas sedimentares arenosas da Formação Caiuá, do Cretáceo, resultado de um processo de sedimentação eólica posterior aos últimos derrames de lava da Formação Serra Geral (EMBRAPA, 1984). Os solos presentes nesta formação são o Latossolo Vermelho-E scuro, Podzól ico Vermelho-Escuro, Podzól ico VermelhoAmarelo e Areias Quartzosas, de textura média e arenosa (EMATER-Paraná, 1998), classificados, no atual sistema brasileiro de classificação de solos, como: Latossolos Vermel hos, Argissol os Vermel hos, Argissolos Vermelho-Amarelos e Neossolos Quartzarênicos, respectivamente (EMBRAPA, 1999). A textura arenosa e os baixos teores de matéria orgânica conferem a estes solos um baixo poder-tampão, diferenciando-os da maioria dos solos do restante do estado. Configura-se, portanto, a necessidade deestabel ecer as rel ações entre os teores deH + Al e o pH SMP para os sol os desta formação, para que a estimativa indireta da acidez potencial, via leitura do pH SMP, seja obtida com al to grau de confiabilidade.

Este trabalho teve por objetivos: (a) avaliar a relação entre os teores de $\mathrm{H}+\mathrm{Al}$, determinados por meio de procedimento titulométrico, após extração com acetato de cálcio $0,5 \mathrm{~mol} \mathrm{~L}^{-1}$, e os valores de pH SMP; (b) avaliar diferentes model os matemáticos que estimem $\mathrm{H}+\mathrm{Al}$ a partir da medida do pH SMP, para os sol os do arenito Caiuá no noroeste do estado do Paraná, com base nas suas propriedades estatísticas.

\section{MATERIAL E MÉTODOS}

O estudo foi realizado no Laboratório de Solos da Universidade Estadual de Maringá, utilizando
150 amostras de solos selecionadas, de acordo com sua procedência, do total enviado por produtores para análise química de rotina durante o ano de 2000. As amostras foram secas ao ar e peneiradas em malha de $2 \mathrm{~mm}$, realizando-se a leitura do $\mathrm{pH}$ em $\mathrm{CaCl}_{2}$ 0,01 mol L-1, pH SMP, determinação de $\mathrm{H}+\mathrm{Al}, \mathrm{Ca}^{2+}, \mathrm{Mg}^{2+}, \mathrm{K}+$ e C orgânico.

$\mathrm{O} \mathrm{pH}$ em $\mathrm{CaCl}_{2}$ foi determinado em uma relação solo/solução de $1 / 2,5$, após 10 min de agitação e 30 min de repouso. Para medir o pH SMP, $10 \mathrm{~cm}^{3}$ de TFSA foram colocados em copos plásticos, adicionando-se $25 \mathrm{~mL}$ de solução de $\mathrm{CaCl}_{2}$ $0,01 \mathrm{~mol} \mathrm{~L}^{-1}$ e $5 \mathrm{~mL}$ de solução-tampão SMP. A solução SMP foi preparada de acordo com Raij \& Quaggio (1983). O conjunto foi agitado por $15 \mathrm{~min}$ a $160 \mathrm{rpm}$ e, após repouso de uma hora, procedeuseà leitura do pH da suspensão de solo com a solução SMP pH 7,5.

A acidez potencial $(\mathrm{H}+\mathrm{Al})$ foi extraída com acetato de cál cio $0,5 \mathrm{~mol} \mathrm{~L}^{-1}, \mathrm{pH} 7,0$ e determinada por titulação com $\mathrm{NaOH} 0,025 \mathrm{~mol} \mathrm{~L}^{-1}$. Em copos plásticos foram adicionados $5 \mathrm{~cm}^{3}$ de TFSA e $75 \mathrm{~mL}$ de solução extratora. Após 15 min de agitação e repouso por uma noite, alíquotas de $25 \mathrm{~mL}$ foram retiradas, procedendo-se à titulação com NaOH $0,025 \mathrm{~mol} \mathrm{~L}^{-1}$ na presença de fenolftaleína al coólica. Todos os procedimentos adotados para a extração da acidez potencial $(\mathrm{H}+\mathrm{Al})$ nas amostras foram efetuados também nas provas em branco, com vistas em quantificar a acidez proveniente deoutras fontes, de modo que a acidez potencial foi determinada subtraindo-se do vol ume consumi do na titulação de cada amostra o volume médio consumi do nas provas em branco, acrescido do fator de correção de 1,1, resultando em incrementos de $10 \%$ para a concentração de $\mathrm{H}+\mathrm{Al}$.

Os teores de $\mathrm{Ca}^{2+} \mathrm{e} \mathrm{Mg}^{2+}$ foram determinados em espectrofotômetro de absorção atômica após extração com KCl $1 \mathrm{~mol} \mathrm{~L}^{-1}$. O K ${ }^{+}$foi extraído por meio do extrator Mehlich-1 e sua determinação foi feita em fotômetro de chama. O carbono orgânico foi determinado pelo método Walkley - Black (EMBRAPA, 1997).

Os dados obtidos, concentração de $\mathrm{H}+\mathrm{Al}$ e pH SMP, foram submetidos à anál ise de regressão, utilizando os procedimentos estatísticos com as rotinas PROG REG ePROG GLM (SAS, 1999).

\section{RESULTADOS E DISCUSSÃO}

As amostras de solo apresentaram ampla variação de $\mathrm{pH}$, em $\mathrm{CaCl}_{2} 0,01 \mathrm{~mol} \mathrm{~L}-1$, de reação fortementeácida aténeutra (Quadro 1). No entanto, esta variação de acidez ativa não acarretou igual variação nos valores de mesma magnitude de pH SMP, considerando a baixa capacidade tamponante das frações (inorgânica e orgânica) 
destes solos. Normalmente, os solos da região noroeste do Paraná apresentam a mineralogia de sua fração argila dominada por minerais do grupo da caulinita e sesquióxidos de ferro e alumínio, que apresentam baixa CTC e teores baixos de matéria orgânica (EMBRAPA, 1984; Costa et al., 1999).

Nos solos utilizados, foi observada uma significativa e positiva correlação (Figura 1) entrea capacidade de troca catiônica (CTC) e os teores de $C$ orgânico ( $F=154,5 ; P>F=0,0001$ ) queconfirmam que estes solos apresentam CTC dependente do teor de C orgânico e baixo val or de CTC dependente da fração inorgânica. No ajuste dos valores de CTC versus teor de $C$, o coeficiente angular da equação de regressão linear obtido, multiplicado por 1.000, pode ser atribuído à CTC dos colóides orgânicos. O valor obtido $\left(435,8 \mathrm{cmol}_{\mathrm{c}} \mathrm{dm}^{-3}\right)$ é bastante próximo dos 445,6 $\mathrm{cmol}_{\mathrm{c}} \mathrm{dm}^{-3}$, obtido por Costa et al. (1999), para os Latossolos do estado do Paraná, e dos $450 \mathrm{cmol}_{c} \mathrm{dm}^{-3}$ utilizados pela EM BRAPA (Camargo et al., 1987), para calcular a CTC da argila livre da matéria orgânica. J á o coeficientelinear da equação de regressão $\left(2,1164 \mathrm{cmol}_{c} \mathrm{dm}^{-3}\right)$ pode ser atribuído à CTC da fração inorgânica destes solos.

Os teores encontrados para o C orgânico, neste conjunto de solos, são baixos (Quadro 1), apresentando como val or médi o 5,84 $\mathrm{g} \mathrm{dm}^{-3}$ e baixa CTC proveniente dos colóides orgânicos, que, somada à contribuição da fração inorgânica, confirmam o baixo tamponamento destes sol os, cujo valor médio de CTC obtido pela soma das bases trocáveis e da acidez potencial é de 4,66 $\mathrm{cmol}_{\mathrm{c}} \mathrm{dm}^{-3}$. Apesar de estar presenteem pequenas quantidades, a fração orgânica é responsável, na média, pela mai or parte da CTC desses solos. I sto é, utilizando o valor médio de $C$ orgânico de $5,84 \mathrm{~g} \mathrm{dm}^{-3} \mathrm{e}$ $435,8 \mathrm{cmol}_{\mathrm{c}} \mathrm{dm}^{-3}$ para a CTC da fração orgânica, obtém-se o valor de $2,55 \mathrm{cmol}_{\mathrm{c}} \mathrm{dm}^{-3}$ para a fração orgânica, o que correspondea 54,6 \% da CTC do sol o.

A elevada correlação positiva entre a acidez potencial e os teores de carbono orgânico, também verificada por Pavan (1983), foi atribuída à capaci dade da sol ução de acetato de cál cio em extrair não somente a acidez trocável, mas também aquela dependente de $\mathrm{pH}$, associada aos grupos funcionais carboxílicos e fenólicos da matéria orgânica.

Os valores de pH SMP ea concentração de H +Al extraídos com solução de acetato de cál cio 0,5 mol L-1 relacionaram-se inversamente, sendo três model os de regressão ajustados aos dados: (a) linear, (b) quadrático e (c) exponencial (Figura 2 e Quadro 2).

Os resultados indicam que os três modelos são estatisticamente significativos a $0,01 \%$ de probabilidade pel o teste $\mathrm{F}$ equetanto a funçãolinear como a quadrática apresentaram el evado coeficiente de determinação $\left(R^{2}>0,90\right)$.

O quadro 3 apresenta a avaliação estatística dos coeficientes dos model os utilizados neste estudo. Tanto o coeficiente de intercepção como o angular,

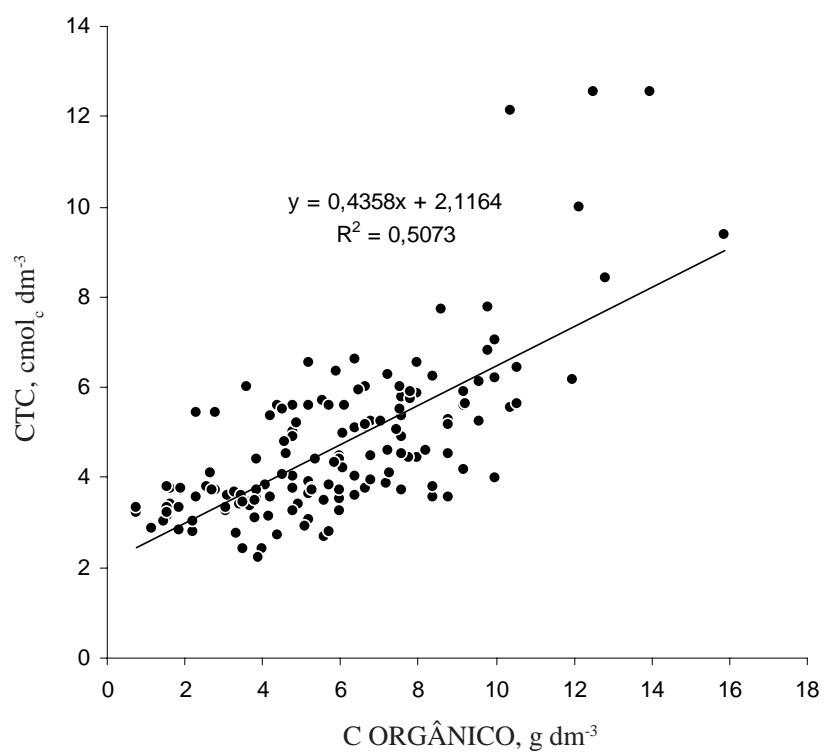

Figura 1. Relação entre a capacidade de troca catiônica e o teor de C orgânico das amostras de solo.

Quadro 1. Valores (mínimo, médio e máximo), desvio-padrão e coefi ciente de variação das características químicas avaliadas das 150 amostras de solo

\begin{tabular}{|c|c|c|c|c|c|c|c|c|}
\hline & $\mathrm{pH} \mathrm{CaCl} 2$ & pH SMP & $\mathbf{H}+\mathbf{A l}$ & $\mathrm{Ca}^{2+}$ & $\mathbf{M g}^{2+}$ & $\mathbf{K}^{+}$ & $\mathbf{T}$ & C \\
\hline & & & & 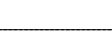 & $\mathrm{mol}_{\mathrm{c}} \mathrm{dm}$ & 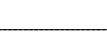 & - & $\mathrm{g} \mathrm{dm}^{-3}$ \\
\hline $\begin{array}{l}\text { Mínimo } \\
\text { Médio } \\
\text { Máximo } \\
\text { Desvio-padrão }\end{array}$ & $\begin{array}{l}3,84 \\
5,14 \\
6,56 \\
0,54\end{array}$ & $\begin{array}{l}5,80 \\
6,82 \\
7,44 \\
0,33\end{array}$ & $\begin{array}{l}0,58 \\
2,14 \\
5,03 \\
0,79\end{array}$ & $\begin{array}{l}0,27 \\
1,58 \\
7,19 \\
1,03\end{array}$ & $\begin{array}{l}0,29 \\
0,81 \\
3,30 \\
0,41\end{array}$ & $\begin{array}{l}0,02 \\
0,14 \\
0,50 \\
0,08\end{array}$ & $\begin{array}{r}2,23 \\
4,66 \\
12,55 \\
1,76\end{array}$ & $\begin{array}{r}0,77 \\
5,84 \\
15,88 \\
2,88\end{array}$ \\
\hline C.V. (\%) & 10 & 5 & 37 & 65 & 50 & 59 & 38 & 49 \\
\hline
\end{tabular}




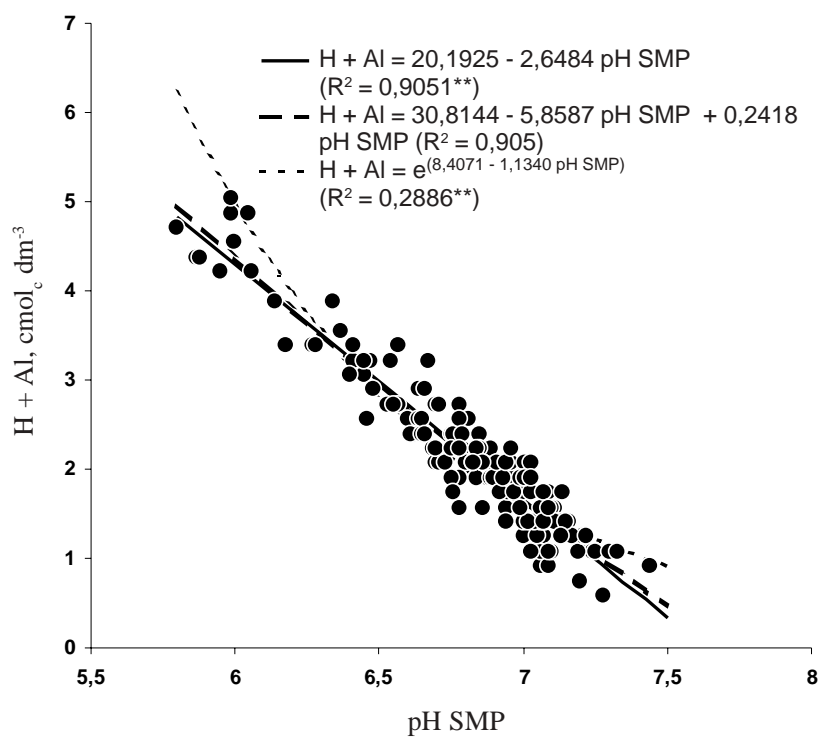

Figura 2. Relação entre teores de $\mathbf{H}+\mathbf{A l}$ extraídos com acetato de cálcio 0,5 $\mathrm{mol} \mathrm{L}^{-1}$ e pH SMP. do modelo linear, são significativos ( $P<0,0001)$, além de apresentarem valores baixos dos errospadrão. O model o quadrático, com $\mathrm{R}^{2}$ ligeiramente superior ao do modelo linear, apresentou valores mais altos dos erros-padrão, além de componente quadrático não-significativo ( $P>0,05)$, o que não contribuiu para melhor explicar a relação entre as variáveis. O model oexponencial conta com seus dois coeficientes significativos ( $P<0,0001$ ) e também apresentou valores reduzidos dos erros-padrão.

As figuras $3 a$ e $4 a$ ilustram a relação entre os valores estimados de $\mathrm{H}+\mathrm{Al}$ pelo modelo e os medidos deH +Al por extração com acetato de cálcio $0,5 \mathrm{~mol} \mathrm{~L}^{-1}$, para os modelos: linear e quadrático, respectivamente. As figuras $3 b$ e $4 b$ mostram a relação entre os erros $(\mathrm{H}+\mathrm{Al}$ medido $-\mathrm{H}+\mathrm{Al}$ estimado) eos val ores estimados deH + Al para estes dois model os. Observam-se, em ambos os modelos, poucos desvios da reta entre os val ores estimados e os val ores medidos e que a distribuição dos erros se dá de forma aleatória, o que, segundo N eter et al.

Quadro 2. Análise de variância e coeficiente de determi nação ajustado para os três modelos de regressão avaliados

\begin{tabular}{|c|c|c|c|c|c|c|c|}
\hline Modelo & FV & GL & SQ & QM & $\mathbf{F}$ & $\operatorname{Pr}>\mathbf{F}$ & $R^{2}$ ajustado \\
\hline $\begin{array}{l}\text { Linear } \\
\mathrm{H}+\mathrm{Al}=\mathrm{a}+\mathrm{b} \mathrm{pH} \mathrm{SMP}\end{array}$ & $\begin{array}{l}\text { Modelo } \\
\text { Resíduo } \\
\text { Total }\end{array}$ & $\begin{array}{r}1 \\
148 \\
149\end{array}$ & $\begin{array}{r}112,5754 \\
11,7174 \\
124,2928\end{array}$ & $\begin{array}{r}112,5754 \\
0,0792\end{array}$ & 1421,92 & 0,0001 & 0,9051 \\
\hline $\begin{array}{l}\text { Quadrático } \\
\mathrm{H}+\mathrm{Al}=\mathrm{a}+\mathrm{b} \mathrm{pH} \mathrm{SMP}+ \\
\mathrm{c}(\mathrm{pH} \mathrm{SMP})^{2}\end{array}$ & $\begin{array}{l}\text { Modelo } \\
\text { Resíduo } \\
\text { Total }\end{array}$ & $\begin{array}{r}2 \\
147 \\
149\end{array}$ & $\begin{array}{r}112,7547 \\
11,5381 \\
124,2928\end{array}$ & $\begin{array}{r}56,3774 \\
0,0785\end{array}$ & 718,27 & 0,0001 & 0,9059 \\
\hline $\begin{array}{l}\text { Exponencial(1) } \\
\left.H+A I=e^{(a+b p H} S M P\right)\end{array}$ & $\begin{array}{l}\text { Modelo } \\
\text { Resíduo } \\
\text { Total }\end{array}$ & $\begin{array}{r}1 \\
148 \\
149\end{array}$ & $\begin{array}{r}20,6388 \\
4,2337 \\
24,8725\end{array}$ & $\begin{array}{r}20,6388 \\
0,0286\end{array}$ & 721,48 & 0,0001 & 0,8286 \\
\hline
\end{tabular}

(1) $R^{2} \cong 1$ - (SQM/SQ resíduo).

Quadro 3. Resultados da avaliação estatística dos três modelos de regressão utilizados para o ajuste dos dados

\begin{tabular}{|c|c|c|c|c|c|}
\hline Modelo & Coeficiente & Estimativa & Erro-padrão & $\mathbf{t}$ & $\operatorname{Pr}>[t]$ \\
\hline Linear & $\begin{array}{l}a \\
b\end{array}$ & $\begin{array}{r}20,1925 \\
-2,6484\end{array}$ & $\begin{array}{l}0,4793 \\
0,0702\end{array}$ & $\begin{array}{r}42,13 \\
-37,71\end{array}$ & $\begin{array}{l}<0,0001 \\
<0,0001\end{array}$ \\
\hline Quadrático & $\begin{array}{l}\mathrm{a} \\
\mathrm{b} \\
\mathrm{c}\end{array}$ & $\begin{array}{r}30,8144 \\
-5,8587 \\
0,2418\end{array}$ & $\begin{array}{l}7,0441 \\
2,1252 \\
0,16\end{array}$ & $\begin{array}{r}4,37 \\
-2,76 \\
1,51\end{array}$ & $\begin{array}{r}<0,0001 \\
0,0066 \\
0,1328\end{array}$ \\
\hline Exponencial & $\begin{array}{l}a \\
b\end{array}$ & $\begin{array}{r}8,4071 \\
-1,1340\end{array}$ & $\begin{array}{l}0,2881 \\
0,0422\end{array}$ & $\begin{array}{r}29,18 \\
-26,86\end{array}$ & $\begin{array}{l}<0,0001 \\
<0,0001\end{array}$ \\
\hline \multicolumn{6}{|c|}{$\begin{array}{l}\text { Linear: } \mathrm{H}+\mathrm{Al}=\mathrm{a}+\mathrm{b} \mathrm{pH} \text { SMP } \\
\text { Quadrático: } \mathrm{H}+\mathrm{Al}=\mathrm{a}+\mathrm{b} \mathrm{pH} \mathrm{SMP}+\mathrm{c}(\mathrm{pH} \mathrm{SMP}) 2 \\
\text { Exponencial: } \mathrm{H}+\mathrm{Al}=\mathrm{e}^{(\mathrm{a}+\mathrm{b} \text { pH SMP })}\end{array}$} \\
\hline
\end{tabular}


(1989) e Montgomery \& Peck (1992), indica uma adequada descrição dos dados por estes modelos.

A relação entre os valores estimados de $\mathrm{H}+\mathrm{Al}$ pel o modelo exponencial e os medidos de $\mathrm{H}+\mathrm{Al}$ por meio da extração com acetato de cálcio $0,5 \mathrm{~mol}^{-1}$ (Figura 5a) ea observação da distribuição dos erros para este modelo (F igura 5b) evidenciam o caráter não-al eatório da distribuição, o que poderia implicar estimativas bastante afastadas dos val ores reais de $\mathrm{H}+\mathrm{Al}$, que, para estes solos arenosos e com reduzidos teores de matéria orgânica, corresponderiam a uma parcela considerável deseu complexo de troca catiônica, com possibilidade de calcular erroneamente, por exemplo, a necessidade de calagem.

Considerando ser o método SMP para avaliação da acidez potencial indireto, necessitando, portanto, de uma equação de regressão que possibilite obter resultados muito próximos dos obtidos via determinação direta, o modelo linear foi o que apresentou mel hor qualidadeestatística, além de ser mais simples que os outros modelos avaliados. O
Quadro 4. Tabela para conversão de valores de pH SMP para acidez potencial $\left(\mathrm{H}^{+}+\mathrm{Al}^{3+}\right)$ nossolos do noroeste do estado do Paraná, utilizando a equação linear H + Al =20,1925-2,6484 pH SMP

\begin{tabular}{|c|c|c|c|}
\hline pH SMP & $\mathbf{H}+\mathbf{A l}$ & pH SMP & $\mathbf{H}+\mathbf{A I}$ \\
\hline & $\mathrm{cmol}_{\mathrm{c}} \mathrm{dm}^{-3}$ & & $\mathrm{cmol}_{\mathrm{c}} \mathrm{dm}^{-3}$ \\
\hline 5,80 & 4,83 & 6,65 & 2,58 \\
\hline 5,85 & 4,70 & 6,70 & 2,45 \\
\hline 5,90 & 4,57 & 6,75 & 2,32 \\
\hline 5,95 & 4,43 & 6,80 & 2,18 \\
\hline 6,00 & 4,30 & 6,85 & 2,05 \\
\hline 6,05 & 4,17 & 6,90 & 1,92 \\
\hline 6,10 & 4,04 & 6,95 & 1,79 \\
\hline 6,15 & 3,90 & 7,00 & 1,65 \\
\hline 6,20 & 3,77 & 7,05 & 1,52 \\
\hline 6,25 & 3,64 & 7,10 & 1,39 \\
\hline 6,30 & 3,51 & 7,15 & 1,26 \\
\hline 6,35 & 3,38 & 7,20 & 1,12 \\
\hline 6,40 & 3,24 & 7,25 & 0,99 \\
\hline 6,45 & 3,11 & 7,30 & 0,86 \\
\hline 6,50 & 2,98 & 7,35 & 0,73 \\
\hline 6,55 & 2,85 & 7,40 & 0,59 \\
\hline 6,60 & 2,71 & 7,45 & 0,46 \\
\hline
\end{tabular}

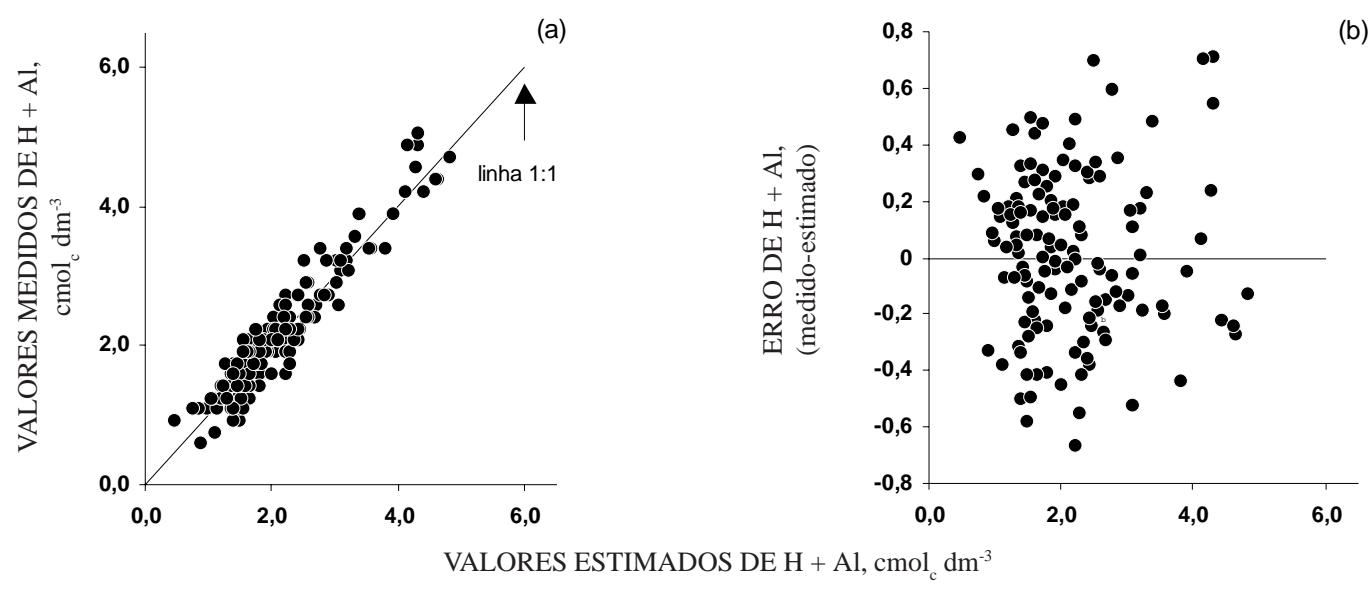

(b)

Figura 3. Relação entre os valores estimados e os medidos de H + Al (a) e relação entre os erros e os valores estimados de H + Al (b) para o modelo linear.
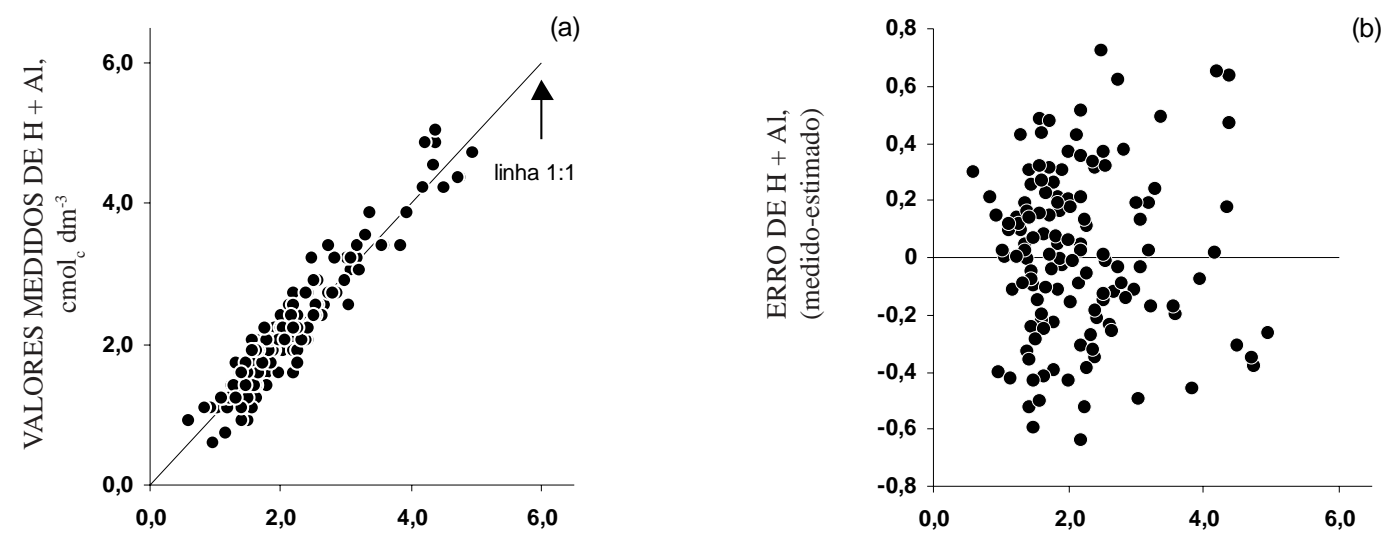

VALORES ESTIMADOS DE $\mathrm{H}+\mathrm{Al}, \mathrm{cmol}_{\mathrm{c}} \mathrm{dm}^{-3}$

Figura 4. Relação entre os valores estimados e os medidos de H + Al (a) e relação entre os erros e os valores estimados de H + Al (b) para o modelo quadrático. 

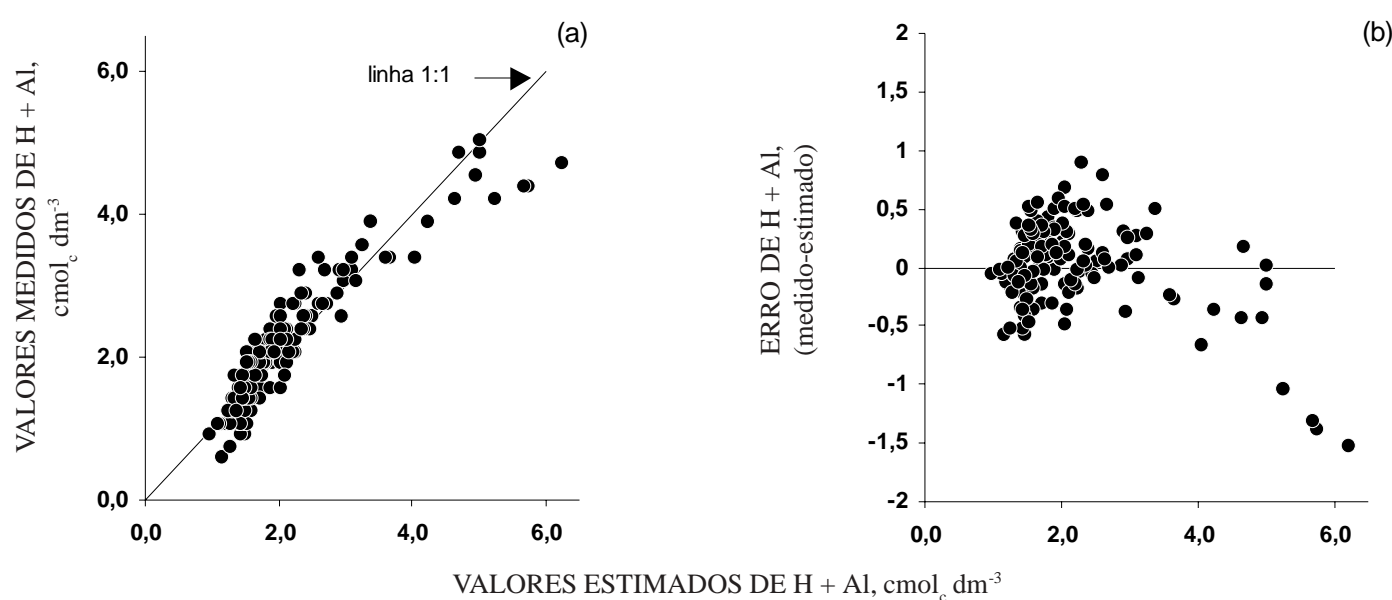

(b)

\section{Figura 5. Relação entre os valores estimados e os medidos de $\mathbf{H}+\mathrm{Al}$ (a) e relação entre os erros e os valores estimados de H + Al (b) para o modelo exponencial.}

quadro 4, construído a partir da equação linear, obtida entre os teores de $\mathrm{H}+\mathrm{Al}$ e os valores de pH SMP, permiteestimar a acidez potencial $(\mathrm{H}+\mathrm{Al})$ a partir dos valores do pH SMP para os solos do noroeste do estado do Paraná.

\section{CONCLUSÕES}

A acidez potencial $(\mathrm{H}+\mathrm{Al})$ dos solos do noroeste do estado do Paraná pode ser determinada indiretamente pela utilização da solução-tampão SMP, empregando-se a equação de regressãolinear $\mathrm{H}+\mathrm{Al}=20,1925-2,6484 \mathrm{pH}$ SMP, que apresentou elevado coeficiente de determinação $\left(R^{2}=0,9051\right)$ e ausência de erros sistemáticos de predição.

\section{LITE RATURA CITADA}

CAMARGO, N.M.; KLAMT, E. \& KAUFFMAN, J.H. Classificação de solos em levantamentos pedológicos no Brasil. B. Inf. Soc. Bras. Ci. Solo, 12:11-33, 1987.

CORRÊA, J .B.; COSTA, P.C.; LOPES, A.S. \& CARVALHO, J .G. Avaliação de $\mathrm{H}+\mathrm{Al}$ pelo método SMP. In: CONGRESSO BRASILEIRO DE PESQUISAS CAFEEIRAS, 12., Caxambu, 1985. Anais. Rio deJ aneiro, Instituto Brasileiro do Café, 1985. p.111-112.

COSTA, A.C.S.; TORINO, C.A. \& RAK,J .G. Capacidade detroca catiônica dos colóides orgânicos e inorgânicos de Latossolos do estado do Paraná. Acta Sci., 21:491-496, 1999.

EMPRESA PARANAENSE DE ASSISTÊNCIA TÉCNICA E EXTENSÃO RURAL - EMATER-PR. Vinculada à Secretaria da Agricultura e do Abastecimento. Arenito Caiuá, Integração Agricultura e Pecuária. Curitiba, 1998. 52p. (I nformação Técnica, 41)
EMPRESA BRASILEIRA DE PESQUISA AGROPECUÁRIA EMBRAPA. FUNDAÇÃO INSTITUTO AGRONÔMICO DO PARANÁ - IAPAR. Levantamento de Reconhecimento dos solos do estado do Paraná. Londrina, 1984. 791p.

EMPRESA BRASILEIRA DE PESQUISA AGROPECUÁRIA EMBRAPA. Serviço Nacional de Levantamento e Conservação do Solo. Manual de métodos de análises do solo. Rio de J aneiro, 1997. 212p.

EMPRESA BRASILEIRA DE PESQUISA AGROPECUÁRIA EMBRAPA. CentroNacional dePesquisa de Solos. Sistema brasileiro de classificação de solos. Rio de J aneiro, 1999. $412 p$.

ERNANI, P.R. \& ALMEIDA, J.A. Comparação de métodos analíticos para avaliar a necessidade de cal cário dos solos do estado de Santa Catarina. R. Bras. Ci. Solo, 10:143-150, 1986.

ESCOSTEGUY, P.A.V. \& BISSANI, C.A. Estimativa de H +AI pelo $\mathrm{pH}$ SMP em solos do Rio Grande do Sul e de Santa Catarina. R. Bras. Ci. Solo, 23:175-179, 1999.

MAEDA, S.; KURIHRA, C.H.; HERNANI, L.C.; FABRICIO, A.C. \& SILVA, W.N. Estimativa da acidez potencial, pelo método do pH SMP, em solos do Mato Grosso do Sul. Dourados, Empresa Brasileira de Pesquisa Agropecuária, 1997. 25p. (Boletim de Pesquisa, 3)

MONTGOMERY, D. \& PECK, E.A. Introduction to linear regression analysis. New York, J ohn Wiley \& Sons, 1992. 527p.

NASCIMENTO, C.W.A. Acidez potencial estimada pelopH SMP em sol os do estado de Pernambuco. R. Bras. Ci. Solo, 24:679$682,2000$.

NETER, J .; WASSERMAN, W. \& KUTNER, M.H. Applied linear models. Boston, Irwin, 1989. 667p.

PAVAN, M.A. Alumínio em alguns solos ácidos do Paraná. Relação entre o alumínio não trocável e solúvel com o pH, CTC, percentagem de saturação de Al e matéria orgânica. R. Bras. Ci. Solo, 7:39-46, 1983. 
PAVAN, M.A.; OLIVEIRA, E.L. \& MIYAZAWA, M. Determinação indireta da acidez extraível do solo $(\mathrm{H}+\mathrm{Al})$ por potenciometria com a solução-tampão SMP. Arq. Biol. Tecnol., 39:307-312, 1996.

PEREIRA, M.G.; VALLADARES,G.S.; SOUZA, J.M.P.F.; PÉREZ, D.V. \& ANJ OS, L.H.C. Estimativa da acidez potencial pelo método do $\mathrm{pH}$ SMP em solos do estado do Rio de J aneiro. R. Bras. Ci. Solo, 22:159-162, 1998.

QUAGGIO, J .A.; RAIJ , B. van \& MALAVOLTA, E. Alternative use of the SMP-buffer solution to determine lime requirement of soils. Comm. Soil Sci. Plant Anal., 16:245260, 1985.

QUAGGIO, J .A. \& RAIJ , B. van. Determinação do pH em cloreto de cálcio e da acidez total. In: RAIJ , B van; ANDRADE, J .C.; CANTARELLA, H. \& QUAGGIO, J.A., eds. Análise química para avaliação da fertilidade de solos tropicais. Campinas, Instituto Agronômico, 2001. 285p.

RAIJ , B. van. Fertilidade do sol o e adubação. Piracicaba, CeresPotafos, 1991. 343p.

RAIJ , B. van; CANTARELLA, H. \& ZULLO, M.A.T. O método tampãoSMP para determinação da necessidade de calagem de sol os do estado de São Paulo. Bragantia, 38:57-69, 1979.
RAIJ , B.van. \& QUAGGIO,J .A. Métodos de análise de solo para fins de fertilidade. Campinas, Instituto Agronômico de Campinas, 1983. 31p. (Boletim Técnico,81)

SAS INSTITUTE. Statistical Analysis System. Procedure guide for personal computers. Version 5. Cary, 1999.

SHOEMAKER, H.E.; MCLEAN, E.O. \& PRATT, P.F. Buffer methods for determining lime requirement of soils with apreciable amounts of extractable aluminum. Soil Sci. Soc. Am. Proc., 25:274-277, 1961.

SILVA, C.A.; AVELLAR, M.L. \& BERNARDI, A.C.C. Estimativa da acidez potencial pelo $\mathrm{pH}$ SMP em solos do semi-árido do nordeste brasileiro. R. Bras. Ci. Solo, 24:689-692, 2000.

SI LVA, E.B.; DIAS, M.S.C.; GONZAGA, E.I.C. \& SANTOS, N.M. Estimativa da acidez potencial pelo pH SMP em solos da região norte do estado de Minas Gerais. R. Bras. Ci. Solo, 26:561-565, 2002

SOUSA, D.M.G.; MIRANDA, L.N.; LOBATO, E. \& KLIEMAN, H.J . Avaliação de métodos para determinar as necessidades de calcário em solos de cerrado de Goiás e do Distrito Federal. R. Bras. Ci. Solo, 4:144-148, 1980.

SOUSA, D.M.G.; MIRANDA, L.N.; LOBATO, E. \& CASTRO, L.H.R. Métodos para estimar as necessidades de calagem em solos dos cerrados. R. Bras. Ci. Solo, 13:193-198, 1989. 